\title{
Sporty Boys and Fashion Girls: Manoeuvring Between Dominant Norms of Gender Identity ${ }^{\mathrm{I}}$
}

Majda Hrženjak, Peace Institute, Ljubljana, Slovenia

\section{Introduction}

S

ocial processes such as globalisation, mobility, labour flexibilisation, shrinking of the welfare systems, changes in the structure and dynamics of the family, and the unpredictability of life courses establish modernity as "risk society" (Beck, 1992) or the "age of uncertainty" (Baumann, 2007) and add to the loosening of the sense of community belonging and the fragmentation and individualisation of society. A fragmented society poses new challenges for the construction of gender identities and the attitude to broader society belongings, such as gender, ethnicity or class. Numerous theorisations reveal how the category of gender is deployed and changed also by the neoliberal ideology and how gender binarism is seemingly reformulated through mass media and the market.

Young women are often held to be key beneficiaries of a range of socio-economic changes that now characterise Western societies while the neoliberal discourse of freedom, choice and individual empowerment are increasingly associated with the category "young women". Girls as a category are in neoliberalism positioned as a new social and economic force in ways previously the reserve of boys. Therefore, successful femininity now involves living a tension between exercising the traditional feminine mode of relationality, physical attractiveness and beauty ideals

I This research work was conducted as part of the Masculinities, Equality, Care Practices (J6-8253) project and the Equality and Human Rights in Times of Global Governance ( $\left.\mathrm{P}_{5}-\mathrm{O} 413\right)$ research programme, both financed by the Slovenian Research Agency. 
and the exhibition of achieved gender equality expressed in individualised agency, freedom and choice previously associated with masculinity (McRobbie, 1991; Gonick, 2004). They must be "bright and beautiful", a "heterofeminine/desirable and successful learner", an "aggressor and nurturer" (Ringrose, 2007, p. 485).

Simultaneously, the discourse of the "crisis of masculinity" poses boys as a "problem", as victims and deprivileged compared to girls (Martino et al., 2009). "The boys' crisis" is believed to be the result of the assertion of feminism and gender equality, and hence the changes in gender roles in society, which are said to be leading to the rising identity insecurity of men/boys, their "softening" and "feminisation". This is believed to be particularly shown in the school environment, which is allegedly feminised, due to which boys are said to lack a "real male" role model. The solution for this allegedly increasing feminisation of boys is looked for in the return to the gender norms of traditional masculinity (Beasley, 2005, p. 180). At the same time, neoliberal consumerism addresses boys in a similar way as girls, i.e. with aestheticisation of masculinity underpinned by the advertising cosmetic and fashion industries. According to Mort (in Haywood \& Mac an Ghaill, 2007, p. 163), these images are based on the narcissistic display of macho representations of male power and virility through outfit and style. This corroborates the trends of aestheticisation, the consumer practices and pluralisation of masculinity which are celebrated by some as "the new forms of inclusive masculinities" (Anderson, 2009), while others warn against the hybridisation and promulgation of hegemonic masculinity so as to adapt to the neoliberal conditions (Bridges and Pascoe, 20I4), which only conceal the existing unequal gender relations.

What should also be pointed out is the growing social emancipation, visibility and recognisability of non-binary gender identities that show an impact by way of loosening perceptions of the gender system as natural, heteronormative, stable and complementary.

This makes young people face several ambivalent situations in the processes of their gender identity construction and negotiation. It seems that in an atomised and fragmented neoliberal society, secure and stable self-identity no longer automatically arises from one's position in the social structure, and in its place, some argue that we are seeing attempts to ground identity in the body as individuals are left alone to establish and maintain values with which to live and make sense of their daily lives. Bodies represent ever more important arenas for the complex formation of gendered identities and power relations, among others using 
"techniques of the self" such as self-care, consumption and leisure, involving practices of grooming, dressing, shaping and decorating bodies. Many studies reveal how diverse masculinities and femininities are currently articulated through consumerism that is written onto the body (Bordo, 1993).

Amid the cacophony of ambivalent representations and meanings of modern masculinities and femininities which young people face, it seems interesting that on the level of the construction of gender identities through body/style young people are continuing to be surprisingly gender-traditional. This was evidenced in interviews with 38 teenagers of both genders aged 13 and $14,{ }^{2}$ the largest share of whom, when asked: "What in your opinion is most typical of boys and what of girls?", unambiguously expressed the view that girls typically dedicate much of their time and energy to their outfit, shopping for clothes, and to fashion, while boys do not pay so much attention to their looks, and are more focused on sports, particularly football. What we thus obtain is the "Lévi-Straussian mythical formula" - girls: boys = fashion : football, which schematically expresses the (traditional) symbolic relations and gender differences as well as differences within each of the two gender groups as constructed by teenagers. The article attempts to analyse the symbolic meanings and empirical effects of this equation on teenagers' engendering. The teenagers' responses corroborate the relational, binary, heteronormative and performative vision of the gender system, in which the conduct of gender-specific body practices plays a constitutive role in the construction of gender identities and relations. The analysis addresses the question of the role of clothing practices in establishing gender identities and identity negotiations and conflicts in young people. I specifically highlight the role played by clothing practices in the construction of masculinity and femininity, while also paying attention to the intersections of gender, class and ethnicity. I analyse the role of clothing practices in constructing gender identities as either dominant or marginalised, traditional or alternative, in both the relationship between boys and girls as well as within groups of boys and girls.

2 Thirty-eight individual semi-structured interviews with eighth-graders in the schools in Slovenian cities and towns of Ljubljana, Koper, Maribor, and Trbovlje were conducted within the Stamina project - Formation of Non-violent Behaviour in School and Leisure Time among Young Adults from Violent Families (Daphne programme). The recruiting of children for the interviews with the consent of their parents was based on a selection made on the basis of preliminary quantitative interviews. Qualitative interviews took place in the school environment, lasted 40 minutes to 2 hours, and were recorded and transcribed. Questions referred to family life, school, spare time and friends, intimate relationships, self-perception, experiences with ethnicity and migrations, attitudes about gender and experiences with violence and bullying. 


\section{Gender and Clothing Practices}

Within culturological studies, authors mainly place fashion within the study of youth-subcultural styles (Hall and Jefferson, 1975). Youth subcultures are defined as "attempts to resolve collectively experienced problems resulting from contradictions in the social structure" (Barker, 2000, p. 323). Analyses focus on subcultures of working-class boys, reducing the specific youth subculture to class subculture. Defining style as rebellion, culturological analysis of youth subcultures highlights the positive, creative and political role of clothing practices in identity negotiations of young people, who establish their sense and meaning of a specific style in social criticism and the creation of alternative identity moduses as well as the social locations of their performance. Style in youth subcultures is defined as opposed to fashion, seen as part of the dominant culture, implying subordination and adaptability.

While culturological studies of youth subcultures address styles and their role in young people, feminist theory distrustfully and critically deals with the meaning of outfit and fashion in the construction of femininity. These analyses articulate "the system of fashion and beauty" as "uniforms of patriarchal fantasy" (Thornham, 2000, p. 147) that establish woman as the consumer subjected to male desire, disciplining woman's body through dominant fashion standards (Bartky, 1988), strengthening stereotypical images of femininity and producing repressive norms of the "real" femininity. These analyses reveal a negative and restrictive role of clothing and other related body practices which they define as the mechanism for discipline, control and adaptation to the existing power relations. Although this discourse also partly allows for the ambivalent nature of fashion as both a creative and oppressive practice, it puts significantly more emphasis on its negative, restrictive and disciplining function serving to submit women to the existing power relations rather than to social criticism, and leading to the stereotypisation, shrinking and homogenisation of alternative identities and social locations rather than their creation.

Both theorisations are shown as relevant, but deficient in addressing the engendering of young people through body practices. Their deficiencies may be summarised as follows: I) by focusing on style as rebellion, culturological analysis of youth subcultures ignores the gender dimension and the pressure from the processes of the construction of gender identities in adolescence; 2) by focusing on fashion as the disciplining of femininity under patriarchal and consumerist norms, the feminist critique of fashion omits masculinity from the analysis and the fact that men are also 
gendered beings subjected to disciplining discourses and gendering practices related to body practices; and 3) both approaches omit heterogeneity within their categories (young, women) and the effects of intersected social locations (ethnicity and class) on gendered identity constructions. I continue by analysing clothing practices as a marker of engendering in girls and boys at the intersection of both theoretical approaches, but from the aspect of the listed deficiencies of the two approaches.

\section{Regulated Body and Techniques of the Self}

When asked, what is most typical of boys and girls, teenagers answered:

Blaž (m, aged I 4): "Well, boys don't use make-up, and they don't have so many clothes as girls do. Girls use make-up, they have different clothes, they don't do the same sports as boys, or boys don't do those, where girls are."

Katja (f, aged I4) says: "Boys don't like shopping, that's first and foremost. Hmm, then they don't feel so strongly about their looks, they don't spend over an hour in the bathroom every morning, I guess. Hmm, but there are exceptions that I know of, and who spend on their looks and all."

Tine (m, aged I4) thinks: "Yes, we're more into bikes or such. Don't know, we do, say, football, which I think girls don't do so much, but also. Girls dress more fashionably than boys or such. They care about their weight, figure, yes. That's it, I guess."

These answers show that teenagers of both genders construct gender difference by referring to "typically feminine" (fashion, taking care of how they look) and "typically masculine" (sports, ignorance of outfit) activities related to the body. Body and looks are shown as an important medium of the production of gendered subjectivity, and different body practices represent the ways and means of identity negotiations, conformity or transgression. Foucault (1991) provided an insight into the "regulated body", for which the dominant discourses inscribe gendered norms, also through the clothing rules and caring for one's looks, which work through feminine and masculine subjectivities. A subject's (self)regulation of their own body while striving for conformity or resistance to the dominant gender norms may be understood as a mechanism for constructing the subject as a male or female. From this aspect, the "techniques of the self" (ibid.), such as engaging in sports in the case of the interviewed boys, or taking care of their outfit in the case of the interviewed girls, can be understood as practices of the normalisation of adolescent gender identity into the normative masculinity and femininity. What happens here is a shift from the natural, biological body as the central mechanism of the naturalisation of sexual difference to the discursive body, suggesting that engendered bodies are produced through discursive norms and power relations 
which are invested in and practised on the otherwise unstable, fragmented and changeable body. What remains unexplained in Foucauldian analyses, as pointed out by Bahovec (2002, p. I84), is sexual difference, that is, the question of why women's bodies are more subjected to cultural norms and ideals than men's, why women are symbolically represented as beings that are more exposed to the gaze of the other, and more burdened by the "need" to take considerable care for their outfits. The answer may be sought in the different ways of the disciplining of masculinity and femininity that take place through gender-specific practices of the regulation of girls' and boys' bodies, producing different attitudes to the body and its aestheticisation. I continue by comparing boys and girls in their attitude to clothing practices to disprove the belief that boys, as opposed to girls, are not under the pressure of being disciplined into the dominant models of masculinity also through body practices, and to show that their disciplining takes place through techniques of the self that are different than in girls.

\section{Hegemonic and Subordinated Masculinities}

The last decades have seen growing interest in research into masculinities, which in gender studies has led to a sensible broadening of the focus from an exclusive orientation to analyses of femininity to the study of the relational dynamics between genders and the heterogeneity within the categories of masculinity and femininity. Connell (20I2) derives from the heterogeneity of the category of men, from multiple masculinities, and says that in every moment different models of masculinity are in the mutual relationships of tension and competitiveness, but only one group of men takes the dominant position of hegemonic masculinity. This group is dominant both in its relation to women and to different modes of masculinity. Although Conell defines the hegemonic masculinity as contextual and relational, that is, as changeable, she points to some central attributes or mechanisms of establishing the hegemonic masculinity that are relatively stable in different contexts. On the relational level, these include radical otherness in relation to femininity, namely, the constant endeavours of men to emphasise and constantly demonstrate their difference from femininity, and normative heterosexuality or homophobia. The inclusion of homophobia as an integral part of hegemonic masculinity establishes gay masculinity as a priori excluded from male hegemony. The body is also an integral part of hegemonic masculinity and, according to Connell (ibid.), in Western culture the sign of hegemonic masculinity is a tall, muscular body. The lack of any of these highlighted features can place 
a boy or man in a subordinate relationship to their peers who possess these characteristics.

The concept of hegemonic masculinity sheds light on the identity challenges of boys who in the sensitive teenage period must construct and demonstrate their gender identity in the "right" way. They have to avoid everything normatively constructed as "girlish" (like an interest in fashion, take care of one's looks), and at the same time to nurture the "masculine looks" of a firm, tough and muscular body that establishes and asserts itself in team collective sports as shown by studies of young boys (Frosh et al., 2002), especially football. Research shows that peer pressure exerts basic social control by constructing boys who conform to the dominant gender norms as popular, and those who transgress these norms as subordinate. The answers of teenage boys and girls, when asked which boys are the most popular at school and why, show how hegemonic masculinity is defined in peer culture. Our study, as well as some other studies (ibid.), give very similar answers in this segment. Boys largely agreed that the most popular among their schoolmates are those who express rebelliousness, opposition to school discipline and disdain for study achievements, excellence in sports, especially football, while contributing to this are also body size and figure along with a clothing style that expresses toughness, nonchalance and rebelliousness. The price that is paid by the subordinate boys, for example, those who prefer to associate with girls or stand out in terms of their bodies for their small size, weight or other special characteristics of the body, who do not like football but prefer conversation, who take care of their looks in an inappropriate way, such as wearing make-up instead of doing sports, is exclusion from the peer group, derision, sometimes physical violence. Studies conducted in English schools show that boys' peer group often punishes the schoolmate who deviates from the dominant norms of masculinity through verbal and psychological violence so that their peers make fun of them that he is gay or a girl (ibid., p. 76). This on one hand represents the feminisation of boys who deviate from the dominant norms of masculinity, with which the peer group establishes the "normal" boyness as opposed to girliness. In this way, femininity is established as radical and inferior "otherness" of masculinity. At the same time, these are homophobic practices that strengthen "normal" boyness through normative heterosexuality. The effect of such derision is twofold: the exclusion of the boy who transgresses the norms of hegemonic masculinity too obviously and the strengthening of the existing gender norms for those who do not transgress them. The space for alternative ways that would not be caught up in gender binarism is thus closed (Hrženjak, 20II). The concept of hegemonic masculinity thereby points 
to the processes of the construction of male gender identity as markedly subjected to normativity and performativity, which require teenagers to evidently put themselves in a relationship and comparison with the norm. Because the majority of boys and men do not meet the ideal of hegemonic masculinity, but nonetheless compare with it and are also constantly controlled by the peer group, the pressure of disciplining is constant.

In the aforementioned British study (Frosh et al., 2002, p. II6), the boys were asked what they liked in girls and what kind of girl they would choose to be their partner. Most of them glorified the girls' "difference" from boys, and constructed them as more serious, capable of making a conversation, being good students etc. As the essential criterion for a potentially more intimate relationship, the boys put forward the girl's feminine' looks and outfit. Although they also pointed out that they can have a good relationship with girls with more boyish looks, talk to them and even let them play football with them, they would not "date" such a girl. This can be explained by the choice and looks of their partner for some boys being in the function of confirming their heterosexuality among their peers. The expressed feminine looks of the girl who occupies the position of the boy's partner, which the girl achieves with the adequate sexualisation of her looks through her outfit, confirms and strengthens the boy's heterosexuality, while a partner with more boyish looks might imply his homosexuality. Thus, what in feminism is interpreted as male domination over the spectacle function of the sexualisation of women's dressing is shown as the dispositive of subordination of boys to the heterosexual norm of hegemonic masculinity and peer pressure. Therefore, external looks and outfit are important for the processes of constructing "normal" male gender identity and for the peer identity negotiation in two ways. First, through the aestheticisation of one's looks - the more the outfit will express toughness, sportiness, physical strength and rebellion against the dominant values of the school culture, such as tidiness, decency, orderliness, good behaviour, subordination etc., the more it will correspond to the norms of hegemonic masculinity; and further on with the sexual choice, that is, the looks of their female partner that must be adequately feminine and sexualised to confirm the heterosexuality of the boy, which is the constitutive norm of hegemonic masculinity. The apparent absence

3 It needs to be pointed out that what is presented here is a very schematic and stereotypical, and accordingly exaggerated, outline of certain segments of the processes of teenagers' engendering that refer to taking care of one's looks. The engendering processes outlined in this article affect some teenagers more than others, some are subjected to them, while others consciously decide to deploy different ways of engendering or are faced with different challenges. In fact, given the assumption that a specific outfit is important for establishing of gender identities, it would be especially interesting to make research into just the opposite strategies: 
of boys' care for their looks paradoxically conceals the fundamental care for their appearance which must unambiguously demonstrate the absence of taking care for one's looks, because this is the distinguishing feature that establishes boys not only as different to but as the opposite of girls. The seeming contempt for the feminised practice of care for looks establishes a distance to everything feminine, which represents the basic norm of hegemonic masculinity. This reveals the gap between the actual living practices of young people and the symbolic norms with which they construct gender difference as binary and irreconcilable.

\section{Intersections of Gender, Ethnicity and Class}

The concept of hegemonic masculinity offers insight into the plurality of men, hierarchy and the positions of power established between men and stemming from their diverse positions in relation to hegemonic masculinity. The second dimension of differentiation is determined by social location or multiple belongings according to ethnicity and class. Both dimensions show mutual overlapping and coeffects. In the continuation, I analyse the position of ethnicised masculinity in relation to the hegemonic norm through the example of clothing practice. Gender is the fundamental, but not isolated category, and along with gender teenagers also "adopt" ethnic and class identity positions. These intersections do not represent processes in which certain a priori existing inherent differences between ethnic groups would automatically produce different types of masculinity and femininity. It is more that processes of the ethnicisation and production of the ethnic "other" a priori exist in society, making the images and discourses of "cultural difference" become intertwined and invested in how masculinity and femininity are performed and experienced. Constructions of cultural differences are important elements of social contexts, in which different ways of masculinity and femininity occur, and this, in turn, establishes ethnicity and class as coeffective dimensions of the generation of masculinity and femininity (Hrženjak, 20II). For example, Haywood and Mac an Ghaill (2007) analyse the complex investments of British working-class teenagers in the adoption of the style of the racialised youth subculture. They define them as an example of how boys use race and ethnicity as a cultural source for establishing teenage male subjectivity, with the racialised coloured "other" representing the central position in relation to which the dynamics of the formation of a white boy's identity takes place. A more detailed illustration was given by Phoenix (2004) in her analysis of the Afro-Caribbean boys who

gender identity constructions that are seemingly indifferent to one's looks and the gendered meaning of clothing systems. 
in British public schools are linked with the image of hyper-masculinity, which is related to the effects of racial stereotypes about black people and their sexuality. Therefore, the assumptions about young black boys were "already there", and these boys are appreciated and admired by their peers due to their apparent hyper- and heterosexuality, rebellious style and audacity. As black and poor immigrants, they are on one hand marginalised and subordinate in the school culture and wider British society, while on the other they are appreciated and admired within the teenage peer culture because they appear "manly", rebellious and they resist the school disciplining. The demonstration of masculinity in the form of hypersexuality, the rebellious style and risky behaviour thus becomes a strategy for reducing their existing social marginalisation and represents the minimum space of power that enables boys from deprivileged ethnic and class positions to acquire a peer status that brings respect.

This interpretive framework can be used in the analysis of ethnicised teenagers in Slovenia and the popularity among them of the "famous" blue tracksuit with a white stripe down the side that some years ago marked the "balkanised masculinity". Interviews show that the immigrants of the first and second generation from former Yugoslavia are not marginalised and excluded among their Slovenian peers, as would be expected, but the opposite; they are popular as the carriers of the "čefur culture" which is expressed in a specific style of clothing, behaving, talking and music. Our interviews show that some boys of the majority and dominant Slovenian ethnicity strive to achieve this specific style of clothing, behaving and talking, which may be explained by the ethnicised and culturalised way of popular boyishness or masculinity. Immigrants from the countries of former Yugoslavia are balkanised and ethnicised as well as constructed as dominant patriarchal men, leisurely, careless, witty, good and passionate football players and popular among girls. Compared to their peers belonging to the ethnic majority, also in Slovenia immigrant teenagers are often economically disadvantaged and at the same time marginalised in broader society, outside their peer group, because they belong to the ethnicised minority. Their great motivation to invest energy in playing football can be understood not only as enjoyment in the game and sports but also as an investment in football as a symbol of the hegemonic masculinity, power and reputation that arises from this position. Therefore, immigrant boys are constructed as conforming to the norms of hegemonic masculinity and as having certain qualities that establish them as popular among peers of both genders. But what is important is that these are not empirical characteristics, but the way members of the dominant ethnicity themselves can ethnicise and construct the immigrant "other" in relation 
to the norms of hegemonic masculinity. This image posteriori influences the behaviour, actions and identity processes of both the immigrant teenagers and those from the dominant culture. For the latter, the imitation of the clothing practices (the tracksuit), style, behaviour and even the linguistic accent represents the strategy of engendering through the "readymade" symbolic elements of ethnicised masculinity that are the closest possible approximation of the specifically contextual normative image of hegemonic masculinity. The tracksuit in this context is a sign indicating the position of hegemonic masculinity at the intersection of ethnicity, gender and class.

\section{Normative and Alternative Models of Femininity}

McRobbie (2009) in her analysis of the embeddedness of modern teenage girls in the mechanisms of "consumer citizenship" and "postfeminist masquerade" examines modern normative modes of femininity, placing them in the "new sexual contract", which behind the apparent emancipation of women establishes new structures of their subordination to modern capitalism. "Fashion girls" construct their femininity under the influence of the dictate of cosmetic and fashion industries that through the postfeminist discourse of advertising and mass media establish girls as empowered and emancipated to take control over their lives as a result of the consumerist "empowerment" and "freedom" of individual consumer choice. Interviews with the eighth-grade girls corroborate the vast presence of this model of girliness and can be perceived in girls' admiration of fashion icons, either famous singers or models. If boys, when asked who they would like to resemble and why, generally answered with the name of a famous sportsman, evoking his sports skills and achievements, girls typically gave the names of famous singers and models due to their looks and outfit.

The construction of the category of popular girls that points to the implicit norms of femininity in relation to which girls must generate their girliness is ambivalent. On one hand, popular girls are defined as those who are popular mainly among teachers at school because they follow the dominant values of the school culture, such as good behaviour, achievement, responsibility, social skills, diligence, orderliness etc. One could say these features symbolically define the traditional image of femininity as subordinate, disciplined and passive, in binary opposition to the masculinised features of rebelliousness, lack of discipline and active attitude. On the other hand, girls who were also defined as popular, or rather, dominant by teenagers, were girls who dressed "conspicuously", with the "conspicuous" dressing being defined as a sexualised dressing by both boys 
and girls. When asked why certain individual girls are popular, one interviewed girl responded: "Because, well, hmm, she just, hm, has bigger boobs, and wears her trousers so tight, right, and her T-shirts with a very low neckline. While I don't like wearing just any low neckline T-shirt that makes everything pop out". In defining this group of girls as popular, both boys and girls seemed to construct masculinity and femininity as consistently symmetric and in mutual opposition and complementarity, as corroborated by two British studies (Frosh et al., 2002; Gleeson \& Frith, 2004). The sexualisation of girls' looks corresponds with the logic of intimate-partner choices in boys, which is dictated by the norm of heterosexuality. In their interviews with 12- to 16-year-old girls in the United Kingdom, Gleeson and Frith (2004, pp. 104-III) reveal the characteristics of the sexualisation of the clothing practices in girls. Some girls avoid pink colour because they construct it as the colour that represents a specific type of femininity - passive, innocent, immature and asexual. They see the rejection of pink as a way of creating a distance from the traditional normative femininity; they choose to use black as the testing and identity negotiation of alternative models of femininity. Their refusal of pink as a colour thus shows ambiguity: on one hand, as the tendency to recognise their sexual maturity and at the same time creating a distance from the traditional norms of femininity. Certain pieces of clothing, such as corsets, short skirts, high-heel shoes that also in wider society are constructed as sexualised and believed to stereotypically mark a specific type of female sexuality, are used by girls consciously and intentionally on certain occasions while going out in the evening and associating with friends. The visibility of the body, in particular of certain body parts and the skin, has always been the object of social control and regulation, while simultaneously exposing the body and disclosing its specific parts are one of the dominant norms of femininity. While social norms dictate that our bodies should be decently covered, at the same time they, ambivalently, encourage teenage girls and young women in particular to disclose certain parts through specific clothing styles. The respondents say that part of the pleasure related to sexualised clothing style stems from the wish to attract the heterosexual male gaze, while at the same time they were positive that they do not do this consciously and on purpose. Instead, they naturalise this strategy of sexualisation by saying: "I really like this style", and thus seemingly ignore the meaning that a particular style or piece of clothing has. They also thus ignore the fact that style and clothes have meanings independent of those ascribed to them by the person who wears them. In this way, girls evade the dominant cultural interpretations of their clothing style and insist on the ambivalence and constant identity negotiations between 
the self-representation and the gender norm. On one hand, girls thus seem to be self-disciplined and self-regulated in accordance with male desire or the need of boys for peer confirmation of their heterosexual masculinity, while on the other girls' sexualisation represents a source of their identity explorations, negotiations, ambiguities, and sometimes transgressions as well as resistance to the dominant gender norms.

McRobbie (1991) researched the sexualisation of the outfits of teenage girls from the aspect of the intersection of gender and class. She analysed the subculture of femininity practised by working-class girls in England in the 1970 s and 1980 s, where the sexualisation of outfit represented one of the major elements in the context of fashion, beauty, romance and pop culture. McRobbie interprets this seemingly conservative and traditional girls' focus on pop culture, looks and romance in the context of their transition from girlhood to womanhood, to their budding sexuality and the period of learning of adult sex roles. And while the school curriculum defines sexuality as a matter of biology, and school culture and families treat teenage girls as asexual beings, pop culture, fashion and beauty are attractive to girls for their serious treatment of teenage sexuality. McRobbie hence defines girl's subculture of looks, romance and pop culture as a rebellion against asexual images of adolescence and femininity, as the confrontation with one's gender and sexual identity, and the related insecurities, challenges and expectations. School culture avoids all this by naturalising gender the identities, sexuality and lifestyles of the middle class.

McRobbie does not define the girly culture of looks, romance and pop culture merely as a technique of the self that leads to the (self)disciplining of girls, but sees it as an ambivalent intermediary in the conflictual relationship between the pressures to conform with the dominant gender norms and looking for one's own identity in girls' identity negotiations in the transitional period of adolescence. In this interpretive framework, taking care for one's looks and specific clothing practices can be a source of empowerment, autonomy, and deviance from the dominant norms of femininity. This may be illustrated by Eva's story. In the interview, Eva (aged 13) reported that she had not been getting along with her parents, among other reasons due to their religious beliefs they had expected her to reconcile her clothing style with Islamic customs. Eva belongs to the gothic subculture: she wears exclusively black colour and conspicuous makeup. As she says, she is excluded for her looks also by her schoolmates of both genders because they perceive her as "other" and different. But, despite her conflict with both her parents and peers, Eva persists in her style. Even more, she says it is in her persisting with her clothing style that she 
finds her firmness and self-confidence to resist on one hand the pressures of her parents to conform to the traditional norms of femininity typical of Islamic culture (which would still establish her as "other" among peers) and the dominant norms of femininity, into which the peer culture tries to normalise her (which would then maintain her as "other" in the family environment). In the conflicted relationship between conformity to gender norms of either the family or the peer environment, Eva tries to negotiate her image of femininity with her unique subcultural clothing style.

\section{Conclusion}

Building on the conception of gender identity as unstable, dynamic, relational and performative, and at the same time extremely normatively burdened, the article has analysed teenagers' narratives of self-perception and the meaning of looks and clothing practices from three aspects: from the aspect of the pressures arising from the conflictual processes and negotiations in the construction of gender identities in adolescence; from the aspect of the role held by clothing practices for the engendering of boys and girls; and from the aspect of heterogeneity within the categories of boys and girls, and the effect of the intersecting social locations (ethnicity and class) on gendered identity constructions. Through the concept of hegemonic and subordinate masculinities, boys were revealed to establish a distance from femininity and homosexuality via self-regulation of their body and clothing practices in the context of peer social control to construct themselves as "real" men. An intersectional perspective was used to understand the hypersexualised and hegemonic body practices in boys who are deprivileged in terms of ethnicity and class, for whom the doing of "real" masculinity helps compensate for social marginalisation; while these practices simultaneously become the model for the formation of hegemonic masculinity in some boys of the dominant culture. Further, girls' clothing practices show the relational dynamics between the norms of masculinity and femininity: on one hand, girls are self-disciplined through sexualised clothing practices that correspond to boys' need to obtain peer confirmation of their heterosexuality; and girls can also use this practice as a source of identity exploration and transgression of the dominant gender norms. This especially applies to subcultural clothing practices that may represent a way of resisting the traditional cultural norms of femininity and postfeminist fashion consumerism, and at the same time provide a space for establishing alternative modes of femininity.

Despite the modern conditions of the fragmentation and individualisation of society, neoliberal rhetorics of "free choice" and the postfeminist discourse of gender equality according to which "all battles have been 
already won" (Gill, 2014), our analysis shows that masculinity and femininity exist only in relation to each other and continue to be constructed through normative everyday discourses and practices, which strongly reflect traditional gender relations. In developing their identities, children draw on culturally available resources in their immediate social networks and society as a whole, with the school environment as a powerful transmitter of gender norms. These resources are strongly gendered with males and females receiving different messages, being constrained differently and having access to different codes. To avoid reinforcing the traditional gender dichotomy and power relations, but also to support children in less rigid, more plural and inclusive identity formations, the school should instead of favouring the existing gender norms systematically enable the expression of alternative ways of doing masculinity and femininity by encouraging the understanding of how gender stereotypes, in coeffect with class and ethnic ascriptions, influence their self-image, self-esteem and the experiencing of their peers. This includes positive recognition of non-binary and non-heteronormative gender identities and a critical reflection of the dominant gender representations passed on by the profit-oriented mass media, popular culture, fashion, advertising and sports industries.

The question arises whether traditional approaches to education that aim to maintain the status quo, reinforcing the current power structures and pursuing pupils' competitiveness that employs fear and shame to motivate their growth, are able to support these processes. As an alternative or at least a complement to traditional educational approaches, feminist pedagogy (Shrewsbury, 1987) with its principle that educators seek to empower students by offering opportunities for critical thinking, self-analysis, and the development of voice, appears to be a viable approach for accomplishing that goal. By democratising the classroom situation, feminist pedagogical approaches create space for dialogue that reflects the multiple voices and realities of the students, discussing the students' own experiences and finding commonalities that individuals thought were only personal matters of their own lives. Encouraging students' agency, both personal and political, brings them to realise their own personal stereotypes that stem from race, class and any other background characteristics. It develops, in joint reflection with students, complex accounts of personal and social reality by questioning the notion of a coherent social subject or essential identity, articulating the multifaceted and shifting nature of identities and oppressions. The critical skills fostered by use of a feminist pedagogical framework encourage recognition and active resistance to societal oppressions. Fostering feminist pedagogical principles can strengthen the school in its function of being a safe and open space in which children and 
young people are allowed to openly speak about their experiences with structural marginalisations. In this vein, the school could and should become the ally of young people while looking for the alternative, egalitarian and solidary lifestyles and social developments needed by modernity.

\section{Literature}

Anderson, E. (2009). Inclusive Masculinity: The Changing Nature of Masculinities. Routledge.

Bahovec Dolar, E. (2002). With your brain and my looks. Telo v kulturnih študijah. In A. Debeljak, P. Stankovič, G. Tomc \& M. Velikonja (Eds.), Cooltura. Uvod v kulturne študije (pp. 175-194). Študentska založba.

Bartky Lee, S. (1988). Foucault, Femininity, and the Modernization of Patriarchal Power. In I. Diamond \& L. Quinby (Eds.), Feminist and Foucault Reflections on Resistance (pp. 6I-87). Northeaster University Press.

Barker, C. (2000). Cultural Studies. Theory and Practice. Sage.

Bauman, Z. (2007). Liquid Time. Living in an Age of Uncertainty. Polity Press.

Beck, U. (1992). Risk Society. Sage Publications.

Bordo, S. (1993). Unbearable Weight: Feminism, Western Culture, and the Body. University of California Press.

Bridges, T., \& Pascoe, C. J. (2OI4). Hybrid Masculinities: New Directions in the Sociology of Men and Masculinities. Sociology Compass, 8(3), $246-258$.

Connell, R. (2012). Moškosti. Krtina.

Foucault, M. (1991). Subjekt in oblast. Zakaj preučevati oblast: vprašanje subjekta. In M. Dolar (Ed.), Vednost-oblast-subjekt (pp. 103-I20). Krtina.

Frosh, S., Phoenix, A., \& Pattman, R. (2002). Young Masculinities. Palgrave Macmillan.

Gleeson, K., \& Frith, H. (2004). Pretty in Pink: Young Women Presenting Mature Sexual Identities. In A. Harris (Ed.), All about the Girls.

Culture, Power, and Identity (pp. I03-II5). Routledge.

Gill, R. (2014). Unspeakable Inequalities: Post Feminism, Entrepreneurial Subjectivity, and Repudiation of Sexism among Cultural Workers. Social Politics: International Studies in Gender, State and Society, 2I(4), $509-528$.

Gonic, M. (2004). The Mean Girl Crisis: Problematizing Representations of Girls Friendships. Feminism \& Psychology, I4(3), 395-400. 
Hall, S., \& Jefferson, T. (1975). Resistance through Rituals. Youth Subcultures in Post-War Britain. Routledge.

Haywood, C., \& Mac an Ghaill, M. (2007). Men and Masculinities, Open University Press.

Hrženjak, M. (20II). Vrstniško nasilje v perspektivi dominantnih konstrukcij ženskosti in moškosti ter sovpadanja strukturnih neenakosti. Šolsko polje, 22(3-4), I3I-I 47 .

Martino, W., Kehler, M., \& Weaver-Hightower, B. M. (Eds.) (2009). The Problem with Boy's Education. Beyond the Backlash. Routledge.

McRobbie, A. (1991). Feminism and Youth Culture. Palgrave Macmillan.

McRobbie, A. (2009). The Aftermath of Feminism. Gender, Culture and Social Change. Sage.

Phoenix, A. (2004). Neoliberalism and Masculinity: Racialization and the Contradictions of Schooling for II to I4-Year-Olds. Youth \& Society, 36, 227-246.

Ringrose, J. (2007). Successful Girls? Complicating Post-Feminist, Neoliberal Discourses of Educational Achievement and Gender Equality. Gender and Education, Ig (4), 47I-489.

Shrewsbury, C. M. (1987). What Is Feminist Pedagogy? Women's Studies Quarterly, I5 (3-4), 6-I4.

Thornham, S. (2000). Feminist Theory and Cultural Studies. Stories of Unsettled Relations. Arnold.

Zaslow, E. (2009). Feminism, Inc. Coming of Age in Girl Power Media Culture. Palgrave Macmillan. 